\title{
Newer Vaccines for Tuberculosis Prevention
}

\author{
Sumitha Nayak
}

\begin{abstract}
As per the latest data from World Health Organization, in the year 2019, a total of 10 million people fell ill with tuberculosis, of which 1.2 million were children, while 1.4 million people died due to tuberculosis. There are 30 high burden countries that are responsible for $87 \%$ of new TB cases. Eight countries account for two-thirds of the total, with India leading, followed by Indonesia, China, the Philippines, and four more countries. An important cog in the wheel of tuberculosis progression is the risk of TB infection progressing to TB disease. To break this wheel, active intervention is essential. A vaccine given to all children can help to confer protection, especially against severe disease forms. Currently, the role of the available BCG vaccine is limited to protection against disseminated TB and miliary TB. Currently, there are at least 15 candidate vaccines at different stages of clinical trials, while one vaccine has entered phase III. These newer vaccines have the potential of combating the disease as we forge ahead to end TB.

Keywords: BCG vaccine, Multidrug-resistant TB, Newer TB vaccines, Tuberculosis.

Pediatric Infectious Disease (2021): 10.5005/jp-journals-10081-1317
\end{abstract}

\section{INTRODUCTION}

As per the latest data from World Health Organization, in the year 2019, a total of 10 million people suffered from tuberculosis, of which 1.2 million were children, while 1.4 million people died due to tuberculosis. ${ }^{1}$

There are 30 high burden countries that are responsible for $87 \%$ of new TB cases. Eight countries account for two-thirds of the total, with India leading, followed by Indonesia, China, the Philippines, and four other countries.

Multidrug-resistant (MDR-TB) and rifampicin-resistant TB (RR-TB) pose a serious public health threat with over 200,000 cases globally, half of which are in India, China, and Russia. Prevention of this disease needs to be seriously re-looked at, as the world works toward the end TB strategy of WHO, part of the Sustainable Development Goal SDP Target 3.3., to be achieved by the year 2030.

\section{TB Prevention}

An important cog in the wheel of tuberculosis progression is the risk of TB infection progressing to TB disease. To break this wheel, active intervention is essential. A vaccine given to all children can help to confer protection, especially against severe disease forms. Currently, the role of the available BCG vaccine is limited to protection against severe forms of TB disseminated TB and miliary TB.

The need for improved vaccines that can help reduce the disease burden has long been felt. Currently, there are several vaccines at different stages of clinical trials, while three vaccines have entered the phase III trials. ${ }^{2}$

\section{Immune Response against TB}

The nature of the response to tuberculosis is immune-mediated. Both the CD4+ and CD8+ T cells play a role in the immunity against TB. The dendritic cells (DCs) migrate from the site of infection in the lung alveoli toward the draining lymph nodes. ${ }^{3}$ These infected DCs produce interleukin 12 (IL-12), which are responsible for the production of interferon-gamma secreting CD4+ cells. In persons with a deficiency of IFN-gamma and IL-12 receptors, there is extreme susceptibility to mycobacterial infection. The most effective
Department of Pediatrics, Shishu: The Children's Clinic, Bengaluru, Karnataka, India

Corresponding Author: Sumitha Nayak, Department of Pediatrics, Shishu: The Children's Clinic, Bengaluru, Karnataka, India, Phone: +91 9742131061, e-mail: snayak2007@yahoo.co.in

How to cite this article: Nayak S. Newer Vaccines for Tuberculosis Prevention. Pediatr Inf Dis 2021;3(3):121-124.

Source of support: Nil

Conflict of interest: None

vaccines are those that stimulate the Th1 helper cell activity, CD4+ and CD8+ responses, and Th1-associated cytokines.

\section{Challenges in Prevention of TB and Limitations of Currently Available BCG VACCINE}

There continues to be a large pool of TB infected populations globally. Also, treatment of TB does not preclude re-infection. Studies have shown that re-infection with new strains of mycobacteria are commoner than previously believed. ${ }^{3}$ The efficacy of the currently available BCG vaccine is variable across the globe. Studies from the UK have shown a $60-80 \%$ protection against pulmonary TB, while populations in Malawi and other tropical countries, including India, have shown no protection ${ }^{3}$ It is postulated that the pre-exposure of these populations to the environmental mycobacteria could interfere with the response elicited to BCG vaccine. ${ }^{3}$ People living with HIV (PLHIV) have a 15-21 times higher likelihood of developing TB infection as current data show almost $69 \%$ of HIV patients co-infected with TB. ${ }^{1}$ This diversity in the efficacy together with the need for better protection, especially of PLHIV has thrown up questions regarding the usefulness of this 100-year-old vaccine, and the need for new anti-TB vaccines.

\section{Attributes of Newer Anti-Tb Vaccines}

While one-third of the population globally is considered to be infected with TB, any new vaccine that is developed should be 
capable of preexposure protection, postexposure prevention of disease occurrence as well as act as an immunotherapeutic to enhance the rate of clearance of mycobacteria. The newer vaccines should also be capable of protecting HIV-infected population who are more prone to TB infection and also protecting those who have already received childhood BCG. The vaccines need to be safer than BCG and provide long-lasting protection against pulmonary TB from the newborn period until adolescence and adulthood. ${ }^{4}$

Some of the major challenges in newer vaccine development are listed in Table 1.

\section{COVID-19 AND TB Control}

The ongoing COVID-19 pandemic has disrupted the diagnosis and management of tuberculosis patients. As the pandemic rages on, the disease burden could worsen, with an increase of 0.2-0.4 million deaths from TB in 2020 alone. $^{5}$ India is one of the four countries that contribute to $44 \%$ of global TB cases and yet has shown a large drop in the number of cases of TB that were diagnosed and treated between January and June 2020. Besides India, Indonesia, the Philippines, and South Africa have shown similar trends. This is worrisome, as it could translate into over 1 million new cases of TB per year between 2020 and $2025 .{ }^{5}$ Better protection against disease by a more effective vaccine would certainly be an important tool to mitigate TB disease.

\section{Need for Newer Tb Vaccines in the Current Scenario}

The emergence of MDR and RR TB has been a game-changer in the control of TB disease, morbidity, complications, and mortality. As a 100-year-old vaccine, the BCG has stood the test of time. However, the elucidation of genetic manipulation of the genome sequence of Mycobacterium TB has spilled out to active research and resulted in the development of newer TB vaccines. ${ }^{3}$ Newer and efficacious TB vaccines would be needed to decrease TB mortality by $90 \%$ and TB incidence by $80 \%$ by 2030 .

The World Health Organization has vocalized the need for newer anti TB vaccines that would be safer, more effective, and work more efficiently to protect neonates and infants. ${ }^{6}$ The vaccines should be capable of protecting subjects with and without latent Mycobacterial infection, safe for use in HIV-infected persons, protect infants, children, and adolescents as well as adult

Table 1: Major challenges in TB vaccine development

\begin{tabular}{ll}
\hline Challenge & Concerns \\
\hline $\begin{array}{l}\text { Infection with M. tuberculosis } \\
\text { does not provide immunity }\end{array}$ & $\begin{array}{l}\text { New TB vaccines must provide a } \\
\text { stronger immune response than } \\
\text { against TB }\end{array}$ \\
$\begin{array}{l}\text { Mne-third of the human } \\
\text { Preventive and } \\
\text { population is infected with TB }\end{array}$ & $\begin{array}{l}\text { immunotherapeutic vaccines are } \\
\text { required } \\
\text { Vaccines with the same degree } \\
\text { Co-infection with HIV is noted }\end{array}$ \\
& $\begin{array}{l}\text { at the same time safe, vaccines } \\
\text { required } \\
\text { New candidate vaccines must }\end{array}$ \\
Large \% of the population & be tested in this cohort of the \\
immunized with BCG &
\end{tabular}

Ref: Eur Respir J 2005;26:162-167 contacts. ${ }^{6}$ The vaccines should have the capability of preventing the disease progression after primary infection as well as reinfections and re-activations in persons with the latent disease. It must be affordable for use globally, especially in low- and medium-income countries (LMIC).

\section{Newer anti-TB Vaccines}

Various newer concepts have been used to develop TB vaccines. The various methods that have been suggested include the following: ${ }^{4}$

- An improved version of the BCG vaccine.

- Follow the prime-boost model, which involves giving the booster dose later as a viral vectored/protein adjuvant vaccine.

- Immunotherapeutic vaccines that help decrease the duration of TB treatment.

\section{Types of Newer Vaccines}

Several vaccines have been undergoing various phases of clinical trials. The vaccines undertrials have been manufactured using varied methods, including the recombinant live vaccine VPM1002, attenuated MTBVAC, mycobacterial whole-cell vaccines, and those with protein or adjuvants. Novel adjuvants provide immunostimulatory mechanisms along with delivery routes for the antigens.

Potential sub-unit vaccines have been developed using the immunodominant TB antigens ESAT-6. In mice experiments, ESAT-6 and antigen $85 \mathrm{~B}$ with a strong adjuvant produced a robust immune response with stable immunological memory for 30 weeks. ${ }^{3}$ Subunit vaccine with Mtb72f in combination with adjuvant ASO1B also produced strong immune responses in mice.

Using the prime-boost strategy could be an important method of developing robust immunity against TB., Vaccine containing Ag85A antigen has shown good results especially in preventing reactivation of TB in the elderly. A recombinant vaccine using the vaccinia virus Ankara as a vector expressing $M$. tuberculosis Ag85A boosts specific CD4+ and CD8+ immunity in the lung lymph nodes. ${ }^{4}$

Recombinant $B C G$ vaccines $r B C G$ is a novel live vaccine that has been undergoing experimental studies. The rBCG30 expressing the Ag85B antigen of M. tuberculosis showed better host survival and stronger immune responses in guinea pigs when challenged with an aerosol of highly virulent $M$. tuberculosis. Another strategy adopted is the $\mathrm{rBCG}$ which alters the permeability of the phagosomes in host cells. Lysteriolysin the enzyme from Listeria monocytogenes has been incorporated with rBCG, which has been shown to improve the MHC Class I presentation of co-phagocytosed cells. Another experimental vaccine includes rBCG secreting diverse cytokines including IL-2, IFN-gamma which enhance the immunostimulatory properties of BCG.

\section{Vaccines in the Pipeline}

There are currently various types of vaccines at different phases of trials. ${ }^{4}$

For the first time in 100 years, there has been a major activity in the development of newer anti-TB vaccines. Around 11 antigens of Mycobacterium have been used in these vaccines under development. $^{4}$

All these newer vaccines target the $\mathrm{CD} 4+$ and $C D 8+T$ cells as well as IFN-gamma, all of which are essential in protection against 
TB. ${ }^{4}$ All vaccines currently in the development pipeline may be used as prime, boost, or immunotherapeutic vaccines. ${ }^{4}$

The vaccines in phase III trials have shown great promise in protection against tuberculosis, both as prophylactic and as postexposure vaccines. They are also being tested for efficacy in PLHIV (Tables 2 and 3).

\section{Phase III Vaccine-VPM 1002}

The VPM 1002 is a recombinant BCG vaccine. It contains the listeriolysin encoding gene (hly) in place of the urease $C$ gene. ${ }^{7,8}$ This listeriolysin is a cholesterol-dependent cytolysin. It forms transmembrane barrel pores in the phagolysosome membrane. Release of antigens and bacterial DNA into the cytosol occurs, results in autophagy, inflammasome activation, and subsequently apoptosis and cell death. ${ }^{8}$ In mice trials, VPM1002 has been shown to protect a post-exposure vaccine. It showed stronger efficacy and is safe for use in immunocompetent and immunodeficient mice. ${ }^{9}$

Phase I and II trials have shown good immunogenicity, efficacy, and safety of this vaccine. ${ }^{8}$ Phase IIB trials in South Africa compare VPM 1002 with BCG in HIV exposed and uninfected and HIV unexposed BCG naive newborns. ${ }^{8}$ Multicentric randomized placebo-controlled phase II/III trials in India on 2,000 adults have been ongoing since 2017. These assess if VPM1002 can prevent recurrence of TB within 1 year after completion of treatment and safety and efficacy in HIV-infected newborns. ${ }^{9-11}$ This vaccine holds the potential for the prevention of TB in the future.

\section{Phase III Vaccine-MIP}

Also known as Immunovac, this is a heat-killed non-pathogenic Mycobacterium (Mycobacterium indicus prani) containing vaccine. ${ }^{11}$ This is being investigated as a prophylactic TB vaccine. It is immunogenic and safe. This vaccine has been approved by DCGI and FDA as an immunoprophylactic and immunotherapeutic in multibacillary leprosy patients as well as for disease prevention in close contacts of patients. ${ }^{12}$ Current trials are underway to assess disease prevention in close healthy household contacts of sputum smear-positive TB patients. ${ }^{11,12}$

Table 2: Global pipeline of vaccines

\begin{tabular}{|c|c|c|c|c|}
\hline Target & Phasel & Phase IIa & Phase I/b & Phase III \\
\hline Newborn & & MTBVAC & & VPM1002 \\
\hline \multirow{4}{*}{$\begin{array}{l}\text { Adult and } \\
\text { adolescents }\end{array}$} & Ad Ag85A & MTBVAC & M72/AS01E & VPM1002 \\
\hline & $\begin{array}{l}\text { ChadOx } \\
\text { MVA } 85 \text { A }\end{array}$ & TBFlu 04L & DAR-901 & MIP \\
\hline & GamTBVac & $\begin{array}{l}\text { BCG Revac- } \\
\text { cination } \\
\text { BMGF }\end{array}$ & H56:1C31 & M. Vaccae \\
\hline & & $\begin{array}{l}\text { ID 93/ } \\
\text { GLASE }\end{array}$ & & \\
\hline \multirow[t]{2}{*}{ Therapeutic } & H56:1C31 & RUTI & & VPM1002 \\
\hline & $\begin{array}{l}\text { ID 93/ } \\
\text { GLASE }\end{array}$ & TB Flu04L & & MIP \\
\hline $\begin{array}{l}\text { Live-atte } \\
\text { Whole-c } \\
\text { Viral vec } \\
\text { Protein a } \\
\text { Ref: Appl Sci } 2\end{array}$ & $\begin{array}{l}\text { huated vaccin } \\
\text { Il inactivated } \\
\text { or vaccine } \\
\text { djuvant vacci } \\
20 ; 10(7): 236\end{array}$ & ragmented va & cine & \\
\hline
\end{tabular}

\section{Phase III Vaccine-M. Vaccae}

This is a whole-cell, heat-inactivated vaccine that is undergoing phase III trials in China., ${ }^{4,11} T$ is safe and immunogenic for use in patients with HIV. ${ }^{4}$ This has already been licensed for use as adjunctive therapy for the treatment of TB in China. ${ }^{11} \mathrm{~A}$ large trial covering over 10,000 individuals with latent TB infection, given the vaccine in a six-dose schedule as a disease preventive, has been recently completed in China, and results are awaited..$^{11-13}$

\section{Conclusion}

This independent review has looked into the limitations of the currently available BCG vaccine, which are overcome by the novel vaccines. As the disease demographics change, accelerated by the COVID outbreak, the challenges in managing TB seem humungous. These newer anti-TB vaccines that are now in the pipeline at different stages of study offer some hope as we race to achieve the SDG goals of the World Health Organization. Almost a hundred years after the introduction of the BCG vaccine, the newer anti TB vaccines undergoing efficacy trials, take us a step forward in the development of efficacious protection against and eradication of tuberculosis.

Table 3: Characteristics of vaccines in phase II and phase III trials

\begin{tabular}{|c|c|c|}
\hline Phase II trials & Type of vaccine & Characteristics \\
\hline MTBVAC & Live attenuated & $\begin{array}{l}\text { Improved safety. Trial } \\
\text { as a replacement for } \\
\text { BCG }\end{array}$ \\
\hline TB/Flu04L & Viral vector vaccine & $\begin{array}{l}\text { Phase lla trials as a BCG } \\
\text { booster in Quantiferon } \\
\text { positive adults }\end{array}$ \\
\hline ID93/GLASE & $\begin{array}{l}\text { Adjuvanted sub-unit } \\
\text { vaccine }\end{array}$ & $\begin{array}{l}\text { Phase II immunogenic- } \\
\text { ity and safety trials in } \\
\text { patients on treatment } \\
\text { for active TB }\end{array}$ \\
\hline RUTI & Whole-cell inactivated & $\begin{array}{l}\text { Polyantigenic vaccine. } \\
\text { trials for safety and } \\
\text { immunogenicity in } \\
\text { MDR-TB }\end{array}$ \\
\hline DAR-901 & Whole-cell inactivated & $\begin{array}{l}\text { Phase Illb trials in BCG } \\
\text { primed adolescents }\end{array}$ \\
\hline H56:IC31 & $\begin{array}{l}\text { Adjuvanted subunit } \\
\text { vaccine }\end{array}$ & $\begin{array}{l}\text { Phase Ilb trials for } \\
\text { safety in reducing } \\
\text { recurrence of TB: HIV }\end{array}$ \\
\hline M72/ASO1E & $\begin{array}{l}\text { Adjuvant fusion } \\
\text { subunit vaccine with } 2 \\
\text { Mtb antigens }\end{array}$ & $\begin{array}{l}\text { Phase Ilb trials in } \\
\text { patients with latent TB } \\
\text { infection }\end{array}$ \\
\hline Phase 3 trials & Type of vaccine & Salient features \\
\hline VPM1002 & $\begin{array}{l}\text { Recombinant, live } \\
\text { vaccine }\end{array}$ & $\begin{array}{l}\text { Trials as a post- } \\
\text { exposure vaccine }\end{array}$ \\
\hline MIP & $\begin{array}{l}\text { Whole-cell inactivated } \\
\text { vaccine }\end{array}$ & $\begin{array}{l}\text { As a prophylactic } \\
\text { vaccine }\end{array}$ \\
\hline M. Vaccae & $\begin{array}{l}\text { Whole-cell inactivated } \\
\text { vaccine }\end{array}$ & $\begin{array}{l}\text { As a disease preventive } \\
\text { vaccine; efficacy in } \\
\text { PLHIV }\end{array}$ \\
\hline
\end{tabular}

Ref: $7,10,11,12$ 


\section{References}

1. World Health Organization, Tuberculosis. Key facts. Available at https://www.who.int/news-room/fact-sheets/detail/tuberculosis. Accessed on 16.12.2020.

2. World Health Organization, Global tuberculosis report 2020: executive summary. Available at: https://apps.who.int/iris/bitstream/ handle/10665/337538/9789240016095-eng.pdf Accessed on 16.12.2020.

3. Martin C. The dream of a vaccine against tuberculosis; new vaccines improving or replacing BCG? Eur Respir J 2005;26(1):162-167. DOI: 10.1183/09031936.05.00109904.

4. Ahsan MJ. Recent advances in the development of vaccines for tuberculosis. Ther Adv Vaccines 2015;3(3):66-75. DOI: 10.1177/2051013615593891.

5. World Health Organisation, Global Tuberculosis report 2020: executive summary. Available at https://apps.who.int/iris/bitstream/ handle/10665/336069/9789240013131-eng.pdf. Accessed on 28.4.2021.

6. World Health Organisation, WHO preferred product characteristics for new tuberculosis vaccines. Available at https://apps.who.int/iris/
bitstream/handle/10665/273089/WHO-IVB-18.06-eng.pdf?ua=1 Accessed on 28.4.2021.

7. Martin C, Aguilo N, Marinova D, et al. Update on TB vaccine pipeline. Appl Sci 2020;10(7):2362. DOI: 10.3390/app10072632.

8. ICMR, Need for effective TB Vaccines. Available at https://itrc.icmr. org.in//index.php/our-work/thematic-areas/vaccines. Accessed on 16.12.2020.

9. Nieuwenhuizen NE, Kulkarni PS, Shaligram U, et al. The recombinant Bacille Calmette-Guerin vaccine VPM1002: ready for clinical efficacy testing. Front Immunol 2017;8:1147. DOI: 10.3389/fimmu.2017.01147.

10. Nieuwenhuizen NE, Kaufmann HES. Next generation vaccines based on Bacille Calmette-Guerin. Front Immunol 2018;9:121. DOI: 10.3389/ fimmu.2018.00121.

11. US National Library of Medicine. Clinical trials.gov. Available at https:// clinicaltrials.gov/ct2/show/NCT03152903. Accessed on 11 Feb2021.

12. Bharathi K. Tuberculosis vaccine development: current status and future directions. J Clin Diagn Res 2019;13(9):AB01-AB04. DOI: 10.7860/JCDR/2019/17230.13164.

13. Weerasuriya CK, Clark RA, White RG, et al. Review symposium New tuberculosis vaccines: advances in clinical development and modelling. J Intern Med 2020;288(6):661-681. DOI: 10.1111/joim.13197. 